\title{
STUDI LINTAS BUDAYA OPTIMISME PADA MAHASISWA PROGRAM STUDI KEBIDANAN
}

\author{
Sugiarti Musabiq, Eko Aditiya Meinarno \\ Fakultas Psikologi Universitas Indonesia \\ Jalan Lingkar Kampus Raya, Pondok Cina, Beji, Kota Depok, Jawa Barat 16424 \\ sugiartipsi@gmail.com
}

\begin{abstract}
Optimism is a critical aspect influencing midwive candidate in their educational phase because it could affect midwifery students in overcoming any obstacles during their study. One of the factors associated with optimism is culture. This study was conducted to examine the differences of optimism given various ethnicities on midwifery students. The study sample was the 476 vocational students majoring in midwifery that were located in the provinces of DKI Jakarta, West Java, Banten, and West Sumatra (women only, age ranged 19-20 years). The LOT-R questionnaire was used to collect data on optimism. The results of One-Way ANOVA test showed that there was no significant difference on optimism in view of ethnicity $(F=1.040 ; p>.05)$. The future studies should involve more participants from various ethnicities in Indonesia, especially ethnicities in the eastern region of Indonesia.
\end{abstract}

Keywords: optimism; culture; midwivary; ethnicity; undergaduate student

\begin{abstract}
Abstrak
Optimisme merupakan karakteristik yang penting untuk ditumbuhkan oleh para bidan dimulai dari masa pendidikan mereka sebagai mahasiswa program kebidanan. Hal tersebut dimaksudkan agar para calon bidan dapat mengatasi berbagai hambatan yang ditemui semasa menjalani pendidikan. Salah satu faktor yang berhubungan dengan tinggi rendahnya optimisme adalah budaya. Penelitian ini dilakukan untuk mengetahui optimisme ditinjau dari berbagai ragam etnis pada mahasiswa program studi kebidanan. Sampel penelitian ini adalah 476 mahasiswi program Diploma III Kebidanan yang berada di wilayah provinsi DKI Jakarta, Jawa Barat, Banten, dan Sumatera Barat (semuanya perempuan, rentang usia 19-20 tahun). Kuesioner LOT-R digunakan untuk mengungkap optimisme. Data yang telah diperoleh kemudian diolah lebih lanjut dengan uji statistik deskriptif dan uji beda menggunakan One-Way ANOVA. Hasil penelitian menunjukkan bahwa tidak terdapat perbedaan signifikan optimisme mahasiswa Kebidanan ditinjau dari ragam etnis $(F=1.040 ; p>.05)$, yang berarti bahwa tidak perbedaan bermakna skor optimisme mahasiswa program studi kebidanan ditinjau dari ragam etnisnya. Penelitian selanjutnya sebaiknya melibatkan lebih banyak partisipan dari lebih banyak etnis di Indonesia, khususnya etnis dari wilayah timur Indonesia.
\end{abstract}

Kata kunci: optimisme; budaya; kebidanan; suku bangsa; mahasiswa

\section{PENDAHULUAN}

Mahasiswa program studi kebidanan sebagai calon bidan, memiliki peran dan posisi penting dalam hal penurunan Angka Kematian Ibu (AKI) dan Angka Kesakitan serta Kematian Bayi (AKB) (Keputusan Menteri Kesehatan Republik Indonesia, 2007). Untuk mengemban tanggung jawab yang cukup berat ini, cukup banyak juga hambatan yang harus dihadapi dalam masa pendidikannya. Hal tersebut antara lain adanya persaingan kerja yang ketat, masih sedikitnya pendidikan kebidanan untuk jenjang Strata 1, 2, dan 3, lambatnya proses pengeluaran STR hingga kemungkinan mengalami trauma akibat kegagalan dalam memberikan pertolongan (Surat Edaran Direktorat Jenderal Pendidikan Tinggi No. 1643, 2011; Pramudiarja, 02 Februari 2012; majalahbidan.com, 2012 Februari 20; Gurdi, 2011). Adanya hambatan-hambatan tersebut kemungkinan dapat menyurutkan 
keyakinan atau ekspektasi mereka akan masa depan mereka di dunia kebidanan. Surutnya keyakinan atau ekspektasi akan masa depan dapat mengarahkan mahasiswa kebidananan pada pesimisme. Oleh sebab itu, penting bagi mahasiswa program studi kebidanan untuk memiliki optimisme agar dapat membuat mereka bertahan dalam menyelesaikan pendidikan tersebut dan menunjang mereka dalam memenuhi tugas tersebut. Optimisme tinggi yang dimiliki mahasiswa kebidanan juga dapat membantu mereka untuk tetap melanjutkan upaya mencapai tujuan yang diharapkan (Carver dkk., 2010; Slutske dkk., 2005, dalam Hanssen dkk., 2015).

Optimisme didefinisikan sebagai ekspektasi positif individu terhadap masa depan (Scheier, Carver, \& Bridges, 1994). Carver dan Scheier (2002) mengatakan bahwa optimisme merupakan sebuah karakteristik dasar pemikiran positif. Optimisme juga merupakan antisipasi positif tentang peristiwa masa depan yang bertindak sebagai faktor penting untuk membantu mengurangi masalah maladaptif seperti distress dan masalah interpersonal (Hong, Kim, \& Kim, 2014). Optimisme didefinisikan sebagai kecenderungan seseorang untuk yakin bahwa dirinya akan mendapatkan hal yang positif dalam kehidupannya (Lee, Brown, Mitchell, \& Schiraldi, 2008). Berdasarkan paparan di atas, dapat disimpulkan bahwa optimisme adalah suatu pemikiran positif atau ekspektasi positif seseorang terhadap masa depan. Orang yang optimis juga lebih memiliki keyakinan tentang masa depan yang membawa mereka untuk melanjutkan upaya menuju tujuan yang diharapkan walaupun dalam pencapaiannya terdapat beberapa kesulitan (Carver dkk., 2010; Slutske dkk., 2005 dalam Hanssen dkk., 2015).

Penelitian tentang optimisme dan kaitannya dengan variabel lain sudah pernah dilakukan, khususnya dalam konteks Indonesia. Partisipan yang menjadi penelitian pun beragam diantaranya mahasiswa, orang dengan HIV AIDS (ODHA), pasien rehabilitas medik, serta ibu dengan anak berkebutuhan khusus. Hasil penelitian optimisme pada mahasiswa menunjukkan bahwa terdapat hubungan yang signifikan antara optimisme dengan self-esteem (Meiliyanti, 2015), perilaku menyontek (Yunissa, 2012), rasa syukur (McCullough, Emmons, \& Tsang, 2002; Dewi, 2015), stres (Chank, Rand, \& Strunk, 2000), dan motivasi berprestasi (Awan, Noureen, \& Naz, 2011). Pada ODHA ditemukan bahwa terdapat hubungan yang signifikan antara optimisme dan kualitas hidup. Penelitian lain menunjukkan terdapat hubungan yang signifikan antara optimisme dengan subjective well-being pada pasien rehabilitasi medis (Carver, Scheier, \& Segerstrom, 2010), hubungan yang signifikan antara optimisme dan keberfungsian keluarga pada ibu dengan anak berkebutuhan khusus, serta hubungan yang signifikan antara optimisme dan selfesteem pada mahasiswa DIII kebidanan. Banyaknya penelitian tersebut membuktikan bahwa variabel optimisme telah banyak dikaitkan dengan varibel lain, namun penelitian yang dikaitkan dengan budaya dan suku di Indonesia belum pernah dilakukan. Hal ini sangat disayangkan karena Indonesia merupakan negara yang kaya akan suku bangsa. Nilainilai yang dianut dalam suatu suku dan budaya dapat memengaruhi sudut pandang individu yang berada pada suku dan budaya tersebut, termasuk dalam hal optimisme (Allik \& Realo dalam Hutz, Midgett, Pacico, Bastianello, \& Zanon, 2014).

Suku bangsa (ethnicity) secara umum dapat diartikan sebagai sense of group yang tergabung dengan karakteristik inti dari asal, sejarah, budaya, bahasa, pengalaman, dan nilai-nilai yang sama (Baumann, 2004; Ratcliffe, 2010). Selain itu, suku bangsa juga merupakan hasil dari diri dan kelompok identitas yang dibuat 
dalam konteks ekstrinsik dan intrinsik serta interaksi sosial (Baumann, 2004). Dapat disimpulkan bahwa identitas suku bangsa akan dijunjung oleh setiap individu dan melandasi nilai-nilai kehidupan pada dirinya karena sudah terinternalisasi. Suku bangsa/ ras merupakan salah satu aspek budaya yang menjadi faktor eksternal dalam memengaruhi tinggi dan rendahnya optimisme. Dalam suatu penelitian, diketahui bahwa hasil perhitungan internal consistency alat ukur LOT-R tidak ditemukan pada ras Afro-Amerika dan hispanik yang merupakan ras minoritas dan tidak ditemukan juga pada individu yang memiliki pendidikan rendah. Oleh karena itu, dapat disimpulkan bahwa optimisme kurang dimiliki pada kelompok ras minoritas dan pendidikan rendah (Hirsch, Britton, \& Conner, 2010). Hal ini terjadi karena di Negara Amerika Serikat, ras minoritas seperti ras Afro Amerika sering menerima diskriminasi dari ras mayoritas (Hirsch dkk., 2010). Di Indonesia sendiri, jika dilihat dari jumlah, terdapat sepuluh suku mayoritas terbesar. Na'im dan Syaputra (2010) menjelaskan sepuluh suku tersebut yaitu Suku Jawa $(40.22 \%)$, Sunda $(15,5 \%)$, Batak $(3,58 \%)$, Sulawesi (3,22\%), Madura (3,03\%), Betawi (2,88\%), Minangkabau (2,73\%), Bugis (2,69\%), Melayu (2,27\%), dan suku asal Sumatera Selatan (2,16\%). Berdasarkan proporsi tersebut dapat diketahui bahwa sebagian besar masyarakat di Indonesia bersuku Jawa. Beradasarkan proporsi tersebut, dapat juga diketahui bahwa lebih dari $50 \%$ suku di Indonesia berasal dari pulau Jawa dan Sumatera. Dengan hasil penelitian dari Hirsch dkk. (2010), maka dapat disimpulkan bahwa Suku Jawa memiliki optimisme yang lebih tinggi dibandingkan dengan suku lainnya. Hal ini pun sesuai dengan sikap hidup orang Jawa yang tidak ingin gagal dalam meraih apa yang diinginkan (Sartini, 2009). Sikap yang tidak ingin gagal inilah yang menunjukkan optimisme pada Suku Jawa.
Penemuan dari penelitian di atas serta pentingnya optimisme pada mahasiswa program studi kebidanan menarik dan mendorong peneliti melakukan penelitian terkait hubungan optimisme dengan aspek kebudayaan seperti suku bangsa. Mengingat bangsa Indonesia terkenal sebagai bangsa yang majemuk atau heterogen dengan beraneka ragam suku bangsa, budaya, agama, dan adat istiadat (tradisi), maka ada kemungkinan faktor tersebut berpengaruh besar pada tingkat optimisme, Hasil dari penelitian ini diharapkan dapat menjadi salah satu referensi untuk memprediksi tingkat optimisme mahasiswa program studi kebidanan berdasarkan suku bangsanya, sehingga dapat ditemukan cara yang tepat untuk meningkatkan optimisme mahasiswa tersebut.

Berdasarkan latar belakang tersebut, maka masalah yang akan dijawab melalui penelitian ini adalah "Apakah terdapat hubungan yang signifikan antara optimisme dan suku bangsa pada mahasiswa program studi kebidanan?" Adapun tujuan penelitian ini adalah ingin mengetahui hubungan antara optimisme dan suku bangsa pada mahasiswa program studi kebidanan. Mahasiswa dengan Suku Jawa diharapkan memiliki tingkat optimisme yang tinggi dibandingkan dengan suku lainnya.

\section{METODE}

Penelitian ini merupakan penelitian kuantitatif dengan desain uji beda. Tujuan dari penelitian ini adalah untuk mengetahui apakah terdapat perbedaan signifikan pada optimisme individu berdasarkan suku bangsanya. Populasi dalam penelitian ini adalah mahasiswa program studi kebidanan di pulau Jawa dan Sumatera. Pulau Jawa dan Sumatera dipilih karena sebagian besar suku mayoritas berasal dari pulau ini. Adapun karakteristik partisipan dari penelitian ini adalah mahasiswa program studi kebidanan, berusia 18-25 
tahun, berasal dari Pulau Jawa atau Sumatera. Jumlah partisipan yang ditargetkan dalam penelitian ini adal 500 partisipan. Metode pemilihan sampel (sampling) yang dilakukan oleh peneliti adalah dengan non-probability atau nonrandom sampling yakni convenience sampling. Partisipan dalam penelitian ini merupakan mahasiswa program Diploma III kebidanan semester 4 dan 6 di wilayah provinsi DKI Jakarta, Jawa Barat, Banten, dan Sumatera Barat, yang memiliki karakteristik suku bangsa yang sesuai dengan wilayah tempat tinggal dan sekolahnya. Hal ini bertujuan untuk meningkatkan kemurnian identitas suku bangsa yang dimiliki individu yang juga selaras dengan lingkungan budaya di tempat tinggalnya atau lingkungan sekolahnya. Mahasiswa yang dipilih merupakan mahasiswa pada semester 4 dan 6 karena pada semester ini mahasiswa sudah mulai melakukan praktek kebidanan. Mahasiswa pada semester ini merasakan secara langsung hambatan dan dinamika selama praktik sehingga peran sikap optimis sangat diperlukan pada masa ini.

Berdasarkan sortir yang telah dilakukan, didapatkan partisipan sebanyak 476 mahasiswa program Diploma III Kebidanan yang memiliki suku bangsa selaras dengan provinsi akademi kebidanannya. Data yang telah terkumpul kemudian diolah secara kuantitaif menggunakan Program Statistical Package for Social Science (SPSS) dengan teknik statistik deskriptif dan One-Way ANOVA untuk melihat signifikansi hubungan antara variabel.

Hipotesis dalam penelitian ini adalah terdapat perbedaan yang signifikan pada optimisme mahasiswa Kebidanan berdasarkan suku bangsanya. Mahasiswa dengan Suku Jawa diharapkan memiliki optimisme yang lebih tinggi dibandingkan dengan suku lainnya.

\section{Pengukuran}

Alat ukur optimisme yang digunakan adalah alat ukur LOT-R. Alat ukur LOT-R dikembangkan oleh Scheier, Carver, dan Bridges (1994) dan telah diadaptasi di Indonesia oleh Isma (2013) serta dilakukan uji keterbacaan $(n=12)$, uji reliabilitas dan validitas $(n=153 ; \alpha=0.51$; validitas $\geq 0.2)$ kembali oleh peneliti, sedangkan suku bangsa diketahui bersadarkan data demografi partisipan pada bagian awal pengisian kuesioner penelitian.

\section{HASIL DAN PEMBAHASAN}

Dalam penelitian ini, peneliti memeroleh data sebanyak 476 partisipan yang merupakan mahasiswa program Diploma III kebidanan. berikut adalah pemaparan mengenai data demografis partisipan berdasarkan kuesioner yang digunakan dalam penelitian.

Tabel 1.

Gambaran Umum Partisipan

\begin{tabular}{lrr}
\hline Karakteristik & \multicolumn{1}{c}{$\mathrm{f}$} & $\%$ \\
\hline Usia & & \\
18 tahun & 15 & 3.1 \\
19 tahun & 189 & 39.7 \\
20 tahun & 185 & 38.9 \\
21 tahun & 64 & 13.4 \\
22 tahun & 19 & 4.0 \\
23 tahun & 3 & 0.6 \\
25 tahun & 1 & 0.2 \\
Provinsi & & \\
Sumatera Barat & 260 & 54.6 \\
DKI Jakarta & 180 & 37.8 \\
Banten & 27 & 5.7 \\
Jawa Barat & 9 & 1.9 \\
Suku Bangsa & & \\
Minang & & \\
Multikultural* & 260 & 54.6 \\
Sunda & 180 & 37.8 \\
\hline Multikultural & 36 & 7.6 \\
\hline
\end{tabular}

*Multikultural merupakan individu yang mengidentifikasikan dirinya lebih dari satu suku bangsa yang tinggal di wilayah ibu kota (DKI Jakarta) 
Sebagian besar partisipan berusia 19 tahun dengan jumlah partisipan sebanyak 189 orang. Berdasarkan identitas suku bangsa, jumlah partisipan terbanyak berasal dari suku bangsa Minang yaitu sebanyak 260 orang partisipan. Dalam penelitian ini, karena mengambil partisipan yang bersekolah di wilayah Ibu Kota Jakarta yang terdiri dari beragam identitas suku bangsa, peneliti menggunakan istilah multikultural yang berarti adanya beragam identitas suku bangsa yang bercampur di suatu wilayah.

Tabel 2.

Gambaran Umum Optimisme

\begin{tabular}{crrr}
\hline $\begin{array}{c}\text { Kategorisasi } \\
\text { Skor }\end{array}$ & $\begin{array}{c}\text { Rentang } \\
\text { Skor }\end{array}$ & \multicolumn{1}{c}{ f } & $\%$ \\
\hline Rendah & $8-14$ & 84 & $17.6 \%$ \\
Sedang & $15-21$ & 35 & $74.2 \%$ \\
Tinggi & $22-24$ & 3 & $8.2 \%$ \\
& & 39 & \\
\hline
\end{tabular}

Nilai mean optimisme partisipan adalah sebesar 17.55 dan standar deviasi (SD) 3 . Berdasarkan persebaran skor total optimisme didapatkan pula persebaran skor optimisme partisipan yang dibagi ke dalam tiga kategorisasi yaitu rendah, sedang, dan tinggi. Sebagian besar partisipan penelitian memiliki tingkat optimisme sedang (cukup optimis) yaitu sebanyak 353 orang (74.2\%).

Analisis uji beda opotimisme antar suku bangsa yang terdapat dalam penelitian dilakukan dengan menggunakan uji OneWay ANOVA. Berdasarkan hasil perhitungan, diketahui bahwa tidak terdapat perbedaan mean skor optimisme berdasarkan suku bangsa $\quad(F=1.040$, $p>.05)$. Artinya adalah suku bangsa tidak berperan dalam menentukan perbedaan mean skor optimisme pada kelompok partisipan penelitian.

Hasil penelitian tersebut berbeda dengan penelitian sebelumnya yang menyatakan bahwa optimisme kurang dimiliki pada kelompok ras minoritas dan pendidikan rendah (Hirsch dkk., 2010), dan penelitian yang dilakukan oleh Chang (1996) tentang adanya pengaruh budaya terhadap optimisme pada mahasiswa Asia Amerika dan Kaukasian Amerika. Perbedaan hasil penelitian tersebut kemungkinan terjadi karena Indonesia merupakan Negara kepulauan terbesar di dunia (Portal Nasional RI., n.d). Setiap pulau-pulau di Indonesia umumnya dihuni oleh suku bangsa atau kelompok sosial tertentu, dengan demikian suku bangsa tertentu menjadi mayoritas di wilayah mereka masing-masing. Sementara menurut penelitian hanya ras minoritas saja yang memiliki optimisme rendah (Hirsch dkk., 2010). Sampel mahasiswa kebidanan yang diambil di wilayahnya masing-masing membuat mereka merasa sebagai mayoritas, dengan begitu hasil penelitian ini berbeda dengan hasil penelitian yang dilakukan oleh Hirsch dkk. (2010) dan Chang (1996). Kemungkinan lain yang menyebabkan perbedaan hasil pada peneltian ini dengan penelitian sebelumnya yaitu persamaan nilai budaya yang dianut meskipun berbeda suku, yaitu budaya kolektivisme. Adanya budaya yang sama secara keseluruhan membuat setiap suku tidak memiliki perbedaan yang signifikan dalam menghadapi suatu masalah atau kejadian. Selain itu, meskipun diketahui suatu suku mayoritas terhadap suku lain di Indonesia, namun tidak terdapat diskriminasi atas suku minoritas sehingga adanya perbedaan optimisme pada suku minoritas dan mayoritas yang disebabkan oleh diskriminasi terhadap suku minoritas (seperti yang ditemukan dalam penelitian Hirsch dkk. (2010) tidak ditemukan di Indonesia.

Dapat disimpulkan hasil dari penelitian ini menunjukkan bahwa tidak terdapat perbedaan yang signifikan pada optimisme berdasarkan suku bangsa pada partisipan mahasiswa Kebidanan di Indonesia, dikarenakan adanya faktor karakteristik masyarakat Indonesia yang tidak 
membeda-bedakan satu suku dengan suku lainnya, adanya kesamaan budaya yang dianut disetiap suku, yaitu kolektivisme, serta adanya rasa sebagai suku bangsa mayoritas saat berada di wilayahnya sendiri.

\section{SIMPULAN}

Berdasarkan hasil penelitian yang dilakukan oleh peneliti, optimisme tidak berhubungan dengan suku bangsa, di mana perbedaan suku tidak berhubungan dengan perbedaaan tingkat optimisme. Adapun saran untuk penelitian selanjutnya dapat mengacu pada dua keterbatasan yang masih ada dalam penelitian ini. Pertama, pada penelitian selanjutnya sebaiknya dilakukan pengukuran khusus terkait identitas kesukuan yang mengukur seberapa dalam individu merasa menjadi bagian dari suku tersebut dan seberapa dalam individu tersebut menginternalisasikan nilai-nilai dari suku tersebut. Kedua, pada penelitian selanjutnya sebaiknya dilakukan penelitian dengan variasi suku yang tersebar dari wilayah timur hingga wilayah barat di Indonesia.

\section{DAFTAR PUSTAKA}

Awan, R. U. N., Noureen, G., \& Naz, A. (2011). A study of relationship between achievement motivation, self concept and achievement in englissh and mathematics at secondary level. International Education Studies, 4, 72-79.

Baumann, T. (2004). "Defining Ethnicity". The SAA Archaeological Record, September, 12-14.

Chank, E. C., Rand, K. L., \& Strunk, D. R. (2000). Optimism and risk for job burnout among working college students: Stress as a mediator. Personality and Individual Differences, 29, 255-263.
Chang, E. C. (1996). Cultural differences in optimism, pessimism, and coping: Predictors of subsequent adjustment in Asian American and Caucasian American college students. Journal of Counseling Psychology, 43, 113123. doi:10.1037/00220167.43.1.113.

Carver, C, S., \& Scheier, M. F. (2002). Optimism. In C. R. Snyder \& S. J. Lopez (Eds.). Handbook of positive psychology. pp. 231-243. New York, NY: Oxford University Press.

Carver, C. S., Scheier, M. F., \& Segerstrom, S. C. (2010). Optimism. Clinical Psychology Review, 30(7), 879-889. doi: 10.1016/j.cpr.2010.01.006.

Dewi, H. U. K. (2015). Hubungan antara optimisme dan bersyukur pada mahasiswa penerima beasiswa bidikmisi Universitas Indonesia (Skripsi tidak dipublikasikan). Universitas Indonesia, Depok.

Gurdi, A. (2011). Liku dan tantangan menekuni profesi bidan. Kompasiana. Diakses dari http://www.kompasiana.com/auliagu rdi/liku-dan-tantangan-menekuniprofesibidan_5500f82aa333118d73512463.

Hanssen, M. M., Vancleef, L. M. G., Vlaeyen, J. W. S., Hayes, A. F., Schouten, E. G. W., \& Peters, M. L., (2015). Optimism, motivational coping and well-being: Evidence supporting the importance of flexible goal adjustment. Journal Happiness Study, 16, 1525-1537. doi:10.1007/s10902-014-9572-x.

Hirsch, J. K., Britton, P. C., \& Conner, K. R. (2010). Psychometric evaluation 
of the life orientation test-revised in treated opiate dependent individuals. International Journal Mental Health Addiction, $\quad 8, \quad 423-431$. doi:10.1007/s11469-009-9224-2.

Hong, E. J., Kim, H. E., \& Kim, J. K. (2014). Defense mechanism and optimism in korean college students. Open Jounal of Social Sciences, 2, 84-89. doi:10.4236/jss.2014.211012.

Hutz, C., Midgett, A., Pacico, J., Bastianello, M. \& Zanon, C. (2014). The relationship of hope, optimism, self-esteem, subjective well-being, and personality in Brazilians and Americans. Psychology, 5, 514-522. doi: 10.4236/psych.2014.56061.

Isma, M. N. P. (2013). Hubungan optimisme dan subjective well-being pada pasien yang sedang menjalani program rehabilitasi medik (Skripsi tidak dipublikasikan). Universitas Indonesia, Depok.

Keputusan Menteri Kesehatan Republik Indonesia. (2007). Standar Profesi Bidan. Jakarta, Indonesia: Kementerian Kesehatan RI.

Lee, H. S., Brown, S. L., Mitchell, M. M., \& Schiraldi, G. R. (2008). Correlates of resilience in the face of adversity for Korean women immigrating to the US. Journal of Immigrant Minority Health, 10, 415-422

Majalahbidan.com. (2012, Februari 20). Indonesia akan mengalami surplus bidan pada 2015. Majalah bidan.com. Diakses dari http://majalahbidan.com.

McCullough, M. E., Emmons, R. A., \& Tsang, J. A. (2002). The grateful disposition: A conceptual and empirical topography. Journal of Personality and Social Psychology,
$82, \quad 112-127 . \quad$ doi:10.1037/00223514.82 .1 .112 .

Meiliyanti, N. A. (2015). Hubungan antara optimisme dan general self-efficacy pada mahasiswa penerima bidikmisi di universitas Indonesia. (Skripsi tidak dipublikasikan). Depok: Universitas Indonesia.

Na'im, A. \& Syaputra, H. (2010). Suku bangsa, agama, dan bahasa seharihari penduduk Indonesia: Hasil sensus penduduk 2010. Jakarta: Badan Pusat Statistik Indonesia.

Portal Nasional RI. (n.d). Geografi Indonesia. Indonesia: Available at: http://www.indonesia.go.id/in/sekilas -indonesia/geografi-indonesia

Pramudiarja, AN. U. (2012, Februari 02). Indonesia akan mengalami surplus bidan pada 2015. health.detik.com. Diakses dari http://health.detik.com.

Ratcliffe, P. (2010). "Ethnic Group". Sociopedia.isa, 1-10.

Sartini, N. W. (2009). Menggali nilai kearifan lokal budaya jawa lewat ungkapan (bebasan, saloka, dan pribasa). Jurnal Ilmiah Bahasa dan Sastra, 5, 28-37.

Scheier, M. F., Carver, C. S., \& Bridges, M. W. (1994). Distinguishing optimism from neuroticism (and trait anxiety, self-mastery, and selfesteem): A reevaluation of the life orientation test. Journal of Personality and Social Psychology, 67, 1063-1078. doi:10.1037//00223514.67.6.1063.

Surat Edaran Direktorat Jendral Pendidikan Tinggi. (2011). Diunduh dari http://luk.staff.ugm.ac.id/atur/SEDirj en1643- 
ET2011MoratoriumProdiKesehatan.p df.

Yunissa, R. D. (2012). Hubungan antara optimisme dan menyontek pada mahasiswa. (Skripsi tidak dipublikasikan). Universitas Indonesia, Depok. 